\title{
A EXPANSÃO DA CANA-DE-AÇÚCAR E SEUS IMPACTOS SOBRE A SEGURANÇA ALIMENTAR
}

\author{
The Expansion of Sugar Cane and its Impact on Food Security
}

\begin{abstract}
RESUMO
O impacto da produção de cana-de-açúcar versus produção de outros alimentos vem sendo discutido em âmbito global, enfatizando a equidade no uso da terra na oferta destes produtos - alimentos e combustíveis. Essa abordagem interfere ainda na composição da estrutura fundiária em que abriga os produtos ofertados e demandados pelos indivíduos. Nesse sentido, o objetivo dessa pesquisa foi analisar se a mudança no uso da terra - alimentos por bicombustíveis - afeta a segurança alimentar. Para alcançar o objetivo proposto, foi utilizado o modelo Shift-Share, que dispõe examinar as culturas que têm a aptidão de substituir determinadas lavouras. Na sequência, realizou-se a Correlação de Spearman com intuito de averiguar a relação entre as culturas. Adotou-se ainda indicadores de especialização e uma análise de série histórica da formatação do número de estabelecimentos e suas áreas a fim de acompanhar a evolução da estrutura fundiária. Os resultados mostraram que embora a expansão da cultura de cana-de-açúcar no estado de Mato Grosso do Sul tenha afetado as áreas de produção de alimentos, ainda não compromete a segurança alimentar.
\end{abstract}

Rafael Forest

Universidade Federal da Grande Dourados

rafael_forest@hotmail.com

Jaqueline Severino da Costa

Universidade Federal da Grande Dourados

jaquelinecosta@ufgd.edu.br

Recebido em: 12/06/2015. Aprovado em: 20/09/2016.

Avaliado pelo sistema double blind review

Avaliador científico: André Luís Ribeiro Lima

\begin{abstract}
The impact of sugarcane production versus the production of other foods has been globally discussed, with emphasis on the fairness of land use in supplying these products - food and fuel. This approach also interferes in the composition of land structure that houses the products offered and demanded by individuals. In this sense, the objective of this research was to analyze whether the change in land use - from food to biofuels - affects food security. To achieve the proposed objective, the Shift-Share model, , which examines the cultures that have the ability to replace certain crops, was used. Subsequently, the Spearman correlation was used to investigate the relations between cultures. Specialization indicators and a time series analysis for formatting the number of establishments and their areas, we also used to monitor the evolution of land ownership. The results showed that, although the expansion of cultivation of sugarcane in the state of MatoGrosso do Sul has affected the food production areas, it does not compromise food safety.
\end{abstract}

Palavras-chave: Matriz Energética, Alimento, Potencial Agrícola.

Keywords: Energy Matrix, Food, Agricultural Potential.

\section{INTRODUÇÃO}

Mesmo em um cenário de grandes avanços tecnológicos e científicos que permite a produção abundante de alimentos, uma quantidade considerável da população mundial ainda vive em situação de insegurança alimentar. Muito embora a alimentação tenha se tornado um direito humano consagrado (BURITY et al., 2010).

Barrett (2010) descreve três pilares para a segurança alimentar: a disponibilidade em seu meio produtivo (terra/oferta), o acesso ao alimento (renda/demanda) e a forma que é utilizada (consumo seguro). Caso decline a produção de alimentos não há garantia da oferta ideal de alimentos, além de haver disparidade nos demais elementos que garantem a segurança alimentar. Como consequência pode haver a elevação dos preços dos produtos agrícolas e restrição ao acesso de alimentos da população mais pobre. Os resultados podem ser fome, magreza extrema, instabilidade social e política.

Nesse sentido, a discussão atual perpassa pelas questões referentes à constante preocupação com o abastecimento de alimentos, visto que as necessidades humanas de alimentos são cada vez maiores em um cenário global de grande crescimento populacional (BIERHALS; FERRAZ, 2012).

Nesse panorama, o Brasil se destaca como um dos maiores produtores de alimentos, sendo importante para o abastecimento interno e mundial. Em 2014, por exemplo, a produtividade brasileira de cereais chegou a 101.398 mil toneladas, colocando o país na quarta posição entre 
os principais produtores mundiais, atrás apenas da China, Estados Unidos e Índia (FAO, 2016). Já na produção total de carne, o país ocupa a terceira colocação com 23.630 mil toneladas, ficando a sua frente a China - 80.926 - e os Estados Unidos - 42.168 (FAO, 2013).

Mesmo com toda a conjuntura mundial e nacional favorável à expansão da fronteira agrícola brasileira para a produção de alimentos, a dissidência que envolve a crescente demanda por fontes alternativas de energia, principalmente as de origem limpa, tem alterado o uso da terra no Brasil, visto que há uma tendência para produção de culturas ligadas ao setor energético, preferencialmente a cana-de-açúcar.

Diante dessa perspectiva, a dicotomia da produção de alimentos versus produção de energia torna-se relevante, visto que existe uma prévia disputa interna sobre qual caminho a agricultura brasileira deve tomar e suas implicações para a dinâmica do uso da terra, o que pode afetar a segurança alimentar, ou seja, se a produção energética impõe restrições à segurança alimentar.

Dada a importância das questões acima citadas, inclui-se nessa discussão o estado de Mato Grosso do Sul, primeiro por ser um grande produtor de alimentos e, segundo, pela grande expansão do setor sucroenergético nos últimos 10 anos. A intensificação da plantação de canade-açúcar se iniciou em 2003, contudo o crescimento em área plantada passou de 300\% entre 2005 a 2012 (IBGE, 2014a). Por outro lado, as lavouras tradicionais como soja, milho, algodão e a pecuária podem estar perdendo espaço para novos produtos como a cana-de-açúcar, principalmente na região Sul do estado (WISSMANN et al., 2014; BITTENCOURT; GOMES, 2014).

Dessa forma o artigo pretende responder a seguinte questão condutora: será que a mudança no uso da terra no Mato Grosso do Sul pode ter impactos sobre a segurança alimentar? Para viabilizar a consecução dessa pergunta, é projetado o objetivo de analisar se a mudança no uso da terra afeta a segurança alimentar. Essa perspectiva abrange a dinâmica no uso da terra entre a cana-de-açúcar e as demais culturas alimentares, a composição da estrutura fundiária e a possível alteração da estrutura fundiária com enfoque produtivo do estado de Mato Grosso do Sul.

\section{REVISÃO BIBLIOGRÁFICA}

A questão da segurança alimentar atualmente é tema recorrente na agenda econômica e social, tanto de países desenvolvidos quanto em desenvolvimento, principalmente quando o debate trata sobre o crescimento da população e da renda. O resultado imediato destas duas variáveis é a tendência no aumento do consumo de alimentos (GARNETT, 2013).

Mas será que todos têm acesso a esses alimentos? A fome parece ser um problema relativamente simples de ser resolvido, uma vez que sobre seu entendimento recai a questão da má ingestão calórica e proteica de alimentos básicos. No entanto, uma das dimensões que acarretam a fome está no confronto da produção de alimentos suficientes para atender certa população, ou seja, na incapacidade de ofertar bens alimentares disponíveis localmente. Neste caso, os indivíduos ficam sujeitos a preços mais elevados praticados a partir das transações entre os mercados.

Ressalta-se que a aplicação do conceito de segurança alimentar inicia-se no meio rural, visto que o cultivo de alimentos deve ser feito em quantidades que satisfaçam as necessidades sociais, pois a disponibilidade de alimentos implica assegurar a sobrevivência da humanidade, além de garantir a estabilidade social e política da sociedade (MALUF, 2000; BARRENT, 2010; BURITY et al., 2010).

Assim as perspectivas de segurança alimentar dependem da compatibilização do crescimento econômico com a equidade social, baseada em proposições de médio e longo prazo que intervenham na realidade dos respectivos sistemas agroalimentares, uma vez que esses são os alicerces produtivos (MACEDO et al., 2009).

De forma genérica, a Organização das Nações Unidas para Alimentação e Agricultura (FAO, 2002) afirma que a segurança alimentar é alcançada quando "todas as pessoas têm acesso físico, social e econômico permanente a alimentos suficientes, seguros e nutritivos, que possam atender às suas necessidades nutricionais e preferências pessoais para uma vida ativa e saudável".

Em contrapartida, coloca-se em evidência a incorporação do discurso ambiental na questão energética dos países desenvolvidos que justificam os investimentos do setor sucroenergético no Brasil, manejando a produção brasileira (LIMA et al., 2014).

Assim em conjunto às necessidades por alimentos, ainda existe o movimento expansionista das lavouras canavieiras proveniente principalmente dos tradicionais grupos originários do estado de São Paulo e região Nordeste, em direção da região Centro-Oeste, localidade que tem apresentado as maiores taxas de crescimento em comparação às demais regiões (LIMA et al., 2014).

Tais culturas são insumos de ampla utilidade, seja na composição alimentar humana e animal, ou para a produção de biocombustível e matriz energética, além de ter alta competitividade no mercado internacional. 
Por muito tempo estudos centravam-se em macrofatores globais para explicar as mudanças do uso da terra, tais como alterações socioeconômicas internacionais e mudanças tecnológicas. Embora, os macrofatores ainda sejam importantes, atualmente vêm ganhando destaque as análises voltadas para os microfatores, principalmente aqueles que remetem ao uso da terra e sua dinâmica social (BRIASSOULIS, 2000).

Watanabe (2009) ressalta que ao analisar os microfatores, notam-se as constantes mudanças que emergem da interação entre vários componentes de todo o sistema, isto é, a soma de pequenas mudanças locais e alocações que reforçam ou cancelam o seu uso. Isto é resultado de múltiplas ações entre os vários agentes com base em condições externas (mercados) e internas (aspirações).

Ademais, a mudança no uso da terra depende da tomada de decisões do homem, enquanto agente econômico, e de fatores institucionais (políticas, legais e econômicos), estes por sua vez podem promover mudanças nas condições econômicas dos agentes econômicos -produtores rurais - pela utilização de instrumentos como cobranças de taxas, subsídios, custo de produção, transporte e tecnologia (LAMBIN et al., 2003).

Barbier et al. (2010) corroboram as questões anteriormente supracitadas afirmando que estas são determinantes para a alocação do uso da terra, principalmente quando se considera o valor da terra sobre diferentes usos competitivos que em última instância vai determinar o seu padrão de uso. Fator que contrasta com a questão da segurança alimentar, pois de acordo com Barret (2010), um dos pilares da segurança alimentar refere-se à disponibilidade ou oferta de alimento, sendo que estes é que deveriam definir o uso da terra.

Sendo assim, a competitividade do uso da terra tem balizado a tomada de decisões sobre que tipo de produto o agente econômico deve produzir (BONELIL, 1994). Nesse sentido, Kohlhepp (2010) enfatiza que a produção de biocombustíveis vem se tornando importante para o país tanto quanto a produção de alimentos, pois podem aumentar os ganhos do produtor mediante mudança no uso da terra, ou seja, o produtor passa a escolher qual produto pode ser mais rentável.

A discussão levantada sobre a produção alimentar e de biocombustíveis, além de trazer a abordagem sobre o uso da terra traz ainda reflexões sobre a estrutura fundiária, que por sua vez complementa o entendimento sobre a dinâmica dos usos e coberturas da terra por apresentar como os estabelecimentos agropecuários estão dispostos para o cultivo de determinadas culturas (D'ANTONA et al., 2011).
Ademais, torna-se conveniente mencionar que a distribuição da terra no Brasil é historicamente concentrada e tem se mantido assim ao longo dos anos, isto é, a grande parcela de área agricultável está aparelhada a poucos indivíduos, fato cuja origem remonta ao período da colonização (SOUZA; LIMA, 2002; SOUZA et al., 2007).

Em particular, programas especiais de desenvolvimento regional atuaram no sentido de incentivar a concentração fundiária, além de beneficiar atividades e regiões específicas e favorecer a produção em larga escala (SOUZA et al., 2007).

Ao analisar esse paradigma, Albuquerque (1987) justificava que a concentração de terra se dava porque existia a preferência por lavouras de exportação, que substituem o cultivo voltado para o mercado interno, pois o mercado externo permite rentabilidade mais elevada e apoio tecnológico para o crescimento da produtividade e aproveitamento de áreas.

No Brasil, as propriedades tecnicamente modernas e com grandes extensões, apropriando-se de interesses e políticas que exaltam a produção de commodities, resultam na afirmação de um agronegócio voltado, em sua maior prioridade, à exportação. Dessa forma, a ideia de que a eficiência econômica na agricultura está diretamente relacionada com o tamanho da propriedade (PAULINO, 2011).

Por conseguinte, as pequenas propriedades também merecem a atenção governamental com políticas de reordenamento fundiário e créditos que viabilizem sua capacidade produtiva.

\section{METODOLOGIA}

\subsection{Fontes de Dados}

O estudo compreende uma análise da série histórica da composição do uso da terra no estado de Mato Grosso do Sul ${ }^{1}$, correspondente aos anos de 2000 a 2012, em que foram consideradas nas análises as culturas temporárias, permanentes e a pecuária de corte bovina. A base de dados referente à produção das culturas temporárias e permanentes tem como origem o Anuário Estatístico da Agricultura Brasileira - AGRIANUAL (2007 e 2013).

Quanto à obtenção das áreas de pastagens, os dados referentes ao ano de 2006 foram extraídos do Censo Agropecuário de 2006 do Instituto Brasileiro de Geografia

${ }^{1}$ De 79 municípios do MS, apenas 78 fazem parte das análises, pois o último município foi legalmente criado após a emancipação do distrito de Costa Rica em 2013. 
e Estatística - IBGE, e os dados entre 2009 a 2012 da Federação da Agricultura e Pecuária de Mato Grosso do Sul - FAMASUL. Por não haver dados suficientes disponíveis e atualizados dos demais períodos em nenhuma base de dados, foi elaborada uma estimativa para os anos 2000, 2001, 2002, 2003, 2004, 2005, 2007 e 2008, assim compondo a série histórica. A composição do cálculo de estimação de área de pastagem relacionou o número total do rebanho por $a^{2} o^{2}$ e a média de animal por hectare.

Os dados para identificar as estruturas dos estabelecimentos quanto ao número de imóveis rurais por classes de áreas e categoria do imóvel foram obtidos a partir do Censo Agropecuário de 2006 do IBGE, para os anos de 1995 e 2006, e do Ministério do Desenvolvimento Agrário - MDA juntamente com o Instituto Nacional de Colonização e Reforma Agrária - INCRA para o $\mathrm{ano}^{2}$ de 2012.

As duas instituições disponibilizam os dados sobre as propriedades rurais em hectares. Inclusive o MDA/ INCRA ainda disponibiliza por módulos fiscais, mas esses foram desconsiderados porque os módulos fiscais podem variar em tamanho por hectare em regiões distintas.

Os parâmetros utilizados para equiparar os dados obtidos sobre as propriedades rurais foram balizados pelo tamanho das propriedades em hectares, assim foram classificadas de minifúndio as propriedades com menos de 10 hectares, pequenas propriedades entre 10 e menos de 100 hectares, médias propriedades de 100 e menos de 1.000 hectares e grandes propriedades acima de 1.000 hectares.

\subsection{Procedimentos de Estimação}

Para verificar o comportamento da produção de determinado produto em detrimento de outro, foi utilizado o indicador de "efeito substituição" do modelo "ShiftShare" que busca determinar o efeito do deslocamento no processo de ocupação de áreas para o conjunto de culturas de determinada região, por uma cultura específica.

O indicador do efeito substituição averigua as possíveis implicações de efeito substituição da expansão da cana-de-açúcar em relação às demais culturas alimentares no estado de Mato Grosso do Sul no período de 2000 a 2012.

Na descrição do modelo, Souza e Lima (2002) ressaltam que a variação da área total ocupada por um produto $j$, ocorrido num intervalo de tempo compreendido entre e pode ser representada pela seguinte expressão:

${ }^{2}$ Os dados do total de rebanho por ano foram extraídos do Anuário Estatístico de Pecuária Brasileira (2007 e 2012) - grupo Informe Economics FNP.
$\mathrm{A}_{j T}-\mathrm{A}_{j 0}$

Que pode ser decomposta em dois efeitos: efeito escala e efeito substituição:

$\mathrm{A}_{j T}-\mathrm{A}_{j 0}=\left(\gamma \mathrm{A}_{j 0}-\mathrm{A}_{j 0}\right)+\left(\mathrm{A}_{j \mathrm{~T}}-\gamma \mathrm{A}_{j 0}\right)$

Em que:

$\left(\gamma \mathrm{A}_{j 0}-\mathrm{A}_{j 0}\right)$

É caracterizado como o efeito escala expresso em hectares, e

$\left(\mathrm{A}_{j \mathrm{~T}}-\gamma \mathrm{A}_{j 0}\right)$

Pode ser definido como o efeito substituição expresso em hectares.

Souza e Lima (2002) definem que é o coeficiente que mede a modificação na área total produzida com todos os produtos considerados na análise entre os períodos iniciais e finais, sendo ele obtido por:

$\left(\gamma \mathrm{A}_{j 0}-\mathrm{A}_{j 0}\right)$

Deste modo se o comportamento de determinado produto dentro do sistema for negativo, tem-se a queda na participação, implicando que um determinado produto foi substituído por outro. De modo oposto, se o produto apresentar valor positivo para o efeito, isto significa que este produto substitui outro.

Ainda assim, deve ser feita uma restrição aos valores obtidos pelo efeito substituição, uma vez que o resultado obtido seja ele positivo ou negativo não quer dizer rigorosamente que o produto substitua, ou seja substituído por outras culturas, mas que apenas uma taxa de incorporação de novas áreas maior/menor do que a taxa global do sistema $(\gamma)$.

Exemplificando a situação, suponha os produtos "A e B" e que a soma total dos dois produtos seja $80 \%$ da área total disponível para seu cultivo. Estabelecendo as regras do "efeito substituição" pode ser verificado que o produto " $A$ " obteve valor positivo enquanto o produto " $\mathrm{B}$ " impetrou valor negativo, na interpretação geral supõe-se que " $\mathrm{A}$ " esteja substituindo o produto " $\mathrm{B}$ " em decorrência dos valores que os representam, no entanto, devido existir um volume de área no sistema produtivo ainda disponível $-20 \%$, não é possível afirmar a substituição, pois "A" pode apenas ter expandido sobre esse excedente.

Mas, de forma generalizada pode-se interpretar então que quando a taxa global do sistema é pequena e se

Organizações Rurais \& Agroindustriais, Lavras, v. 18, n. 3, p. 273-288, 2016 
uma cultura tem efeito substituição positiva é bem provável que esteja substituindo outras culturas da área, ou seja, é uma situação dinâmica em que uma cultura amplia em área mais que o sistema produtivo como um todo.

Dessa forma, para garantir interpretação mais condizente com a dinâmica sobre o efeito de substituição, foi realizada ainda uma análise de correlação entre as variáveis, já que, no primeiro momento, apenas obtevese o parecer entre as culturas que têm propensão a serem substituídas e as que substituem, mas não podendo julgar se realmente elas sobressaem uma sobre a outra, alterando a área de produção.

Utilizou-se o coeficiente de Correlação de Spearman, devido a não linearidade das variações de substituição entre as culturas. Para a análise da correlação, segundo o seu grau de importância, consideram-se as seguintes expressões: $\leq-0,5$ e $\geq 0,5$. A análise sugere respectivamente substituição entre culturas e sequência de mesmo padrão entre culturas. A expressão é dada da seguinte forma:

$\mathrm{r}_{\mathrm{s}}=\frac{6 \sum_{i=1}^{n} d_{i}^{2}}{\mathrm{n}\left(\mathrm{n}^{3}-1\right)}$

Em que é o valor encontrado pela correlação entre as culturas analisada, e:

$n=$ número de períodos da análise; $d i=$ é a diferença encontrada entre os postos de duas variáveis.

A Tabela 1 relaciona as variáveis utilizadas no estudo e suas respectivas descrições. Para a análise, utilizou-se o valor da área colhida de cada cultura, visto que esta permite estabelecer o quanto um determinado produto pode ocupar determinada região.

Logo, para verificar se a expansão da cana-de-açúcar alterou a estrutura fundiária do estado de Mato Grosso do Sul e identificar as áreas com maior concentração foram calculados, conforme Tabela 2 e Tabela 3: Quociente locacional, Coeficiente de Especialização e Índice de Theíl.

Conforme afirmam Abdala e Ribeiro (2011), o "Quociente Locacional" é uma medida para avaliar o grau relativo de concentração de uma determinada atividade numa região específica para todas as culturas produtivas. Os valores inferiores a (1) significam que determinada cultura no município observado é pouco expressivo para o estado de MS, já valores acima de (1) significam uma expressão da cultura superior à verificada no estado.

Os mesmos autores definem que o "Coeficiente de Especialização" é uma medida que procura verificar o grau de especialização de determinada região comparando a participação percentual da composição das atividades no local com a participação percentual da composição das atividades no Estado e constitui um índice de especialização produtiva. Se, significa que a composição de

TABELA 1 - Nomenclatura das áreas de culturas colhidas em MS

\begin{tabular}{|c|c|}
\hline Variável & Descrição \\
\hline Varcan00/12 & área colhida de cana-de-açúcar entre os anos de 2000 a 2012 por municípios de MS \\
\hline Varsoj00/12 & área colhida de soja entre os anos de 2000 a 2012 por municípios de MS \\
\hline Varmil00/12 & área colhida de milho entre os anos de 2000 a 2012 por municípios de MS \\
\hline Varpast00/12 & área de pastagem entre os anos de 2000 a 2012 por municípios de MS \\
\hline Varsor00/12 & área colhida de sorgo entre os anos de 2000 a 2012 por municípios de MS \\
\hline Vararro00/12 & área colhida de arroz entre os anos de 2000 a 2012 por municípios de MS \\
\hline Vartrig00/12 & área colhida de trigo entre os anos de 2000 a 2012 por municípios de MS \\
\hline Varalgo $10 / 12$ & área colhida de algodão entre os anos de 2000 a 2012 por municípios de MS \\
\hline Varfeij00/12 & área colhida de feijão entre os anos de 2000 a 2012 por municípios de MS \\
\hline Varmand00/12 & área colhida de mandioca entre os anos de 2000 a 2012 por municípios de MS \\
\hline Vardemtemp00/12 & área colhida com demais culturas temporárias entre os anos de 2000 a 2012 por municípios de MS \\
\hline Varperm00/12 & área colhida com culturas permanentes entre os anos de 2000 a 2012 por municípios de MS \\
\hline Varáreamed & total de área dividido pelo número de estabelecimentos \\
\hline Árealav00/12 & total de área utilizada com lavouras temporárias entre os anos de 2000 a 2012 \\
\hline Alim1 & soma das áreas das culturas alimentares do estado de MS, incluindo a cana-de-açúcar \\
\hline Alim2 & soma das áreas das culturas alimentares do estado de MS, excluindo a cana-de-açúcar \\
\hline
\end{tabular}

Fonte: Elaborado pelos autores

Organizações Rurais \& Agroindustriais, Lavras, v. 18, n. 3, p. 273-288, 2016 
culturas agropecuárias deste é universalmente equivalente à estrutura apresentada pelo estado; inversamente, quanto mais próximo de (1) for o mais especializada é a estrutura agropecuária produtiva deste município.

Já o "Índice de Theil" permite aferir o grau de especialização de uma região. Ao contrário dos outros indicadores apresentados, este índice é um indicador bruto, que compara a expressão de uma atividade em relação ao conjunto de atividades da própria região eliminando-se, deste modo, a discussão inerente à definição de uma região de referência. Assim, o grau de especialização obtido através do Índice de Theil depende apenas da estrutura setorial da região em análise (ABDALA; RIBEIRO, 2011).

A escolha das três medidas foi necessária para a análise, permitindo classificar de forma imediata a posição das regiões (municípios).

\section{RESULTADOS E DISCUSSÃO}

A avaliação feita sobre o uso da terra sul-matogrossense atende às culturas que contribuem de alguma maneira para atender as necessidades alimentares. Apesar das commodities nem sempre servirem como alimento diretamente ao ser humano, em algum momento a mesma retornará sobre outra forma alimentar, por exemplo, alguns cereais podem não ser consumíveis in natura, mas podem ser utilizados para a composição da ração (insumo) animal.
Seguindo a concepção sobre a análise alimentar, foi realizada uma avaliação histórica de área plantada dos principais cultivos no MS, assim a Figura 1 colabora para o entendimento que envolve o efeito substituição da área plantada.

Verifica-se, por exemplo, que a produção de trigo entre os anos de 2000 a 2005 teve um crescimento contínuo, e a partir do ano seguinte, começa a perder área plantada, e sucede concomitantemente, no período em que a cana-de-açúcar passa a receber maior investimento no estado de MS e, ampliam-se as regiões produtoras (CORDEIRO, 2008; DOMINGUES, 2011). Vale ressaltar ainda que assim como o trigo, a cultura de milho ${ }^{3}$ também é lavoura de inverno e necessariamente são concorrentes naturais por áreas cultiváveis (MELLO e BRUM, 2013).

Segundo Ribas (2007), a cultura do sorgo ainda é uma cultura incipiente no estado de MS, sendo uma espécie cultivada apenas em certas regiões que apresentam baixa produtividade de outros grãos e também, as épocas de plantio e colheita estão associadas ao milho, implicando uma relação de substituição implícita para essas culturas.

${ }^{3}$ No estado de Mato Grosso do Sul o modelo predominante agrícola de verão é o cultivo da soja e no outono-inverno o cultivo pode ser substituído pelo milhosafrinha ou pelo trigo.

TABELA 2 - Fórmulas: Quociente locacional; Coeficiente de Especialização e Índice de Theíl.

\begin{tabular}{ccc}
\hline Quociente Locacional & Coeficiente de Especialização & Índice de Theil \\
\hline $\mathbf{Q L}=\frac{\mathbf{X r j} / \mathbf{X r}}{\mathbf{X p j} / \mathbf{X p}}$ & $\mathrm{CE}=\frac{1}{2} \sum_{j=1}^{n}\left|\frac{X p j}{X p}-\frac{X r j}{X r}\right|$ & $I T=\sum_{j=1}^{n}\left|\frac{X r j}{X r} * \log \left(\frac{X r j}{X r}\right)\right|$ \\
\hline
\end{tabular}

Fonte: Elaborado pelos autores.

TABELA 3 - Variáveis e descrições para Quociente Locacional, Coeficiente de Especialização e Índice de Theíl

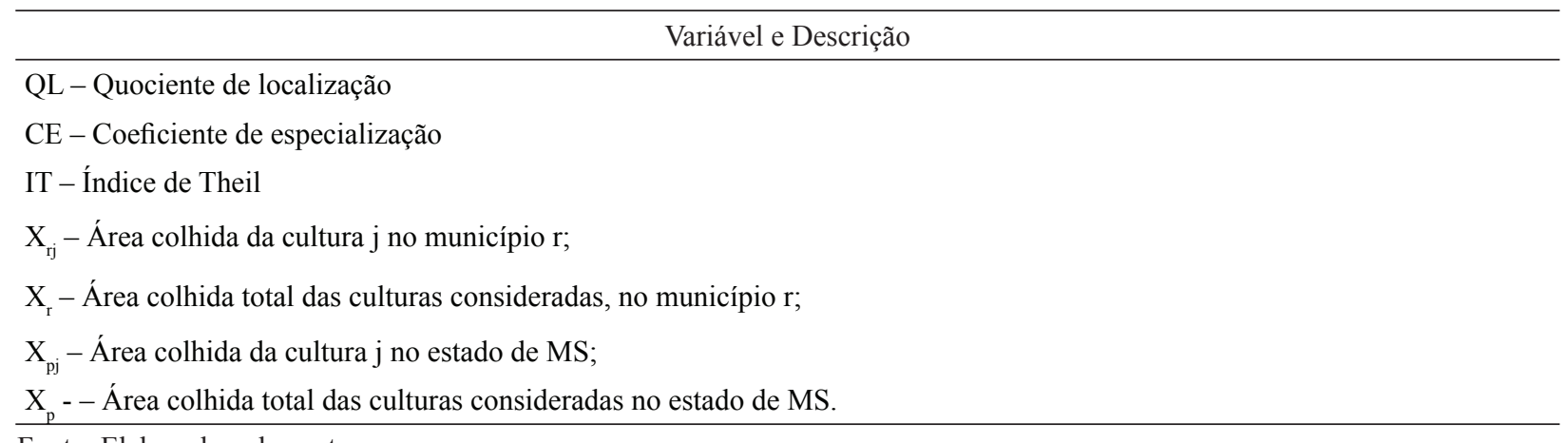




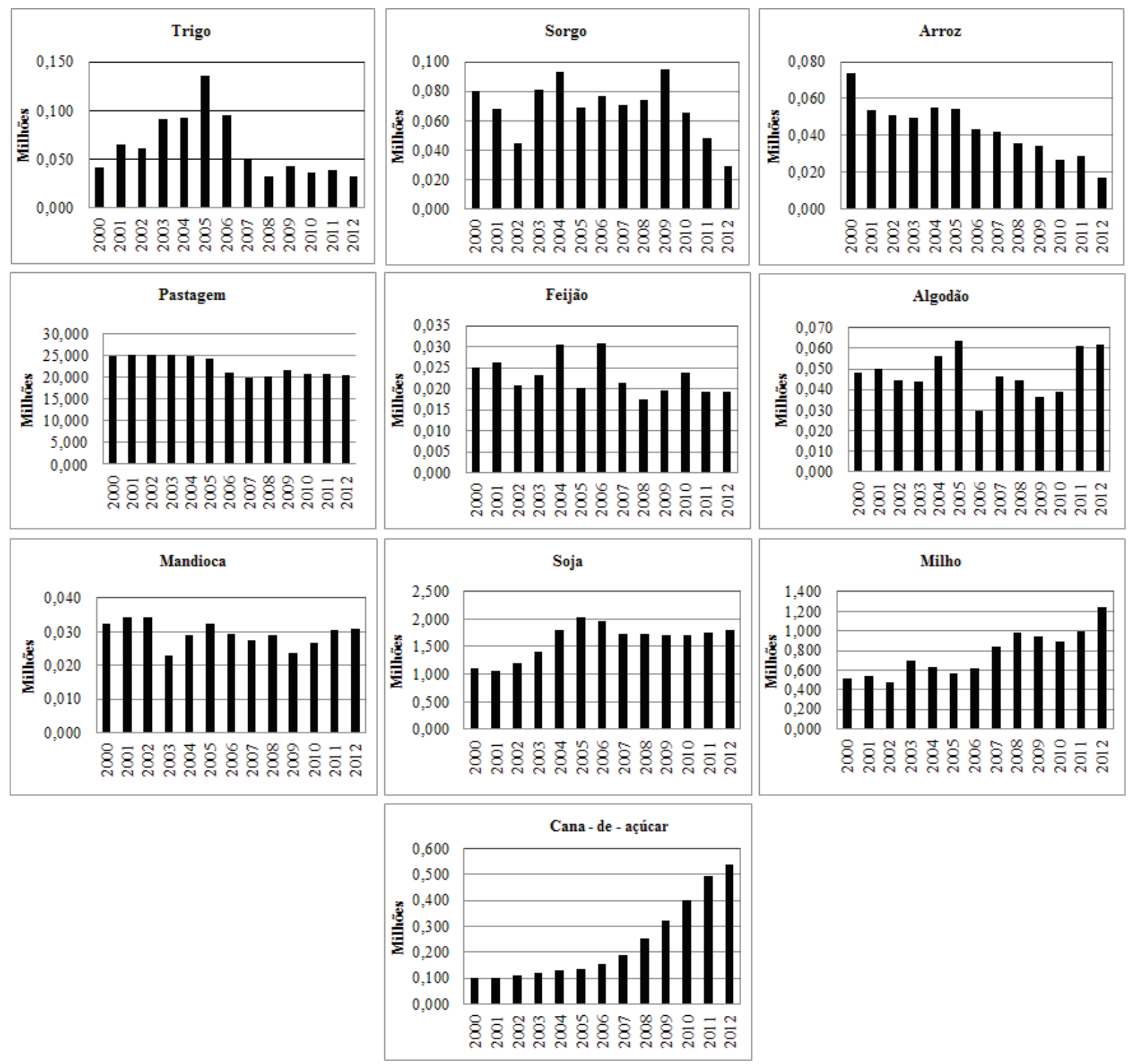

FIGURA 1 - Evolução da área plantada em hectares das culturas alimentares entre 2000 a 2012 Fonte: IBGE. Elaborado pelos autores

Outra lavoura que constantemente reduz a área plantada é o arroz, conforme a Conab (2012) o fator crítico está ligado às regiões de fronteira agrícola devido à competição de produtos de melhor comercialização, especialmente o milho, a soja e cana-de-açúcar.

Em relação às áreas de pastagens, a redução pode estar ocorrendo de forma similar àquela ocorrida no estado de São Paulo com a substituição pela plantação de cana-de-açúcar. Schlesinger (2010) explica que os pecuaristas optaram em arrendar suas áreas para usinas e plantar cana em função da rentabilidade e garantia de venda da produção pelo tempo de vida da planta, que varia entre cinco e seis anos.

Os produtos feijão e algodão apresentam área plantada em constante oscilação, mas ainda é considerada estável. Respectivamente, um possui pouca importância 
comercial o que limita sua expansão, resumindo-o, a pouca expressividade e a quantidade produzida satisfaz o consumo interno; enquanto o outro é impulsionado pela indústria têxtil nacional, pois é a que mais consome esta matéria-prima para a fabricação de fios (CONAB, 2012).

Entretanto outros subprodutos do algodão também são relevantes, principalmente aqueles revertidos para alimentação de ruminantes e aves, tem-se então o farelo do algodão. Segundo a Conab (2013), a produção brasileira de 2012 de 3 milhões de toneladas de caroço de algodão e o processamento desses resultam em $16 \%$ de óleo de algodão e $45 \%$ de farelo de algodão.

A redução da área de soja na safra de 2006 e em alguns anos posteriores são decorrentes do abandono de áreas menos produtivas, em vista da falta de rentabilidade, embora, a soja tenha aumentado sua produtividade, e essa correção na produtividade advém do plantio em áreas mais produtivas (CONAB, 2007). Adverte-se que a safra de soja vem aumentando sua área de produção em detrimento daquelas advindas da redução das áreas de algodão, feijão e arroz, além de abertura de novas áreas e uso de pastagens (CONAB, 2012).

A produção de milho está associada à produção externa, dessa forma a plantação está condicionada aos estoques de outros países. O país possui duas safras anuais do milho, e a segunda safra do ano, denominada milho safrinha, tem maior contribuição para o estado de Mato Grosso do Sul, pois a preferência dos produtores na primeira safra é pela produção de soja, uma vez que esta tem maior rentabilidade, assim fazendo a rotação da cultura com milho (CONAB, 2012).

Enquanto isso, o fortalecimento do setor canavieiro no MS retoma a década de 2000, com incentivo fiscal do governo para aumentar a produção do etanol (biocombustível) e pelo interesse de investidores externos no setor sucroenergético que se encontrava em ascensão. Esse reflexo é notado ao longo do tempo, mais precisamente a partir de 2005, vindo a cana-de-açúcar a ocupar áreas destinadas a outros cultivos (CENTENARO, 2012; LIMA et al., 2014).

A tendência de abertura de novas usinas e a expansão dos canaviais se mantêm nas principais regiões onde a cana-de-açúcar está em crescimento, como por exemplo, em Mato Grosso do Sul.

A figura exibida anteriormente apresenta o comportamento da área plantada das principais culturas produzidas pelo estado do Mato Grosso do Sul. A partir dela é possível verificar que enquanto algumas culturas perdem espaço, a cana-de-açúcar assume posição de destaque com um aumento da área plantada. Contudo, para certificar dessa possível substituição da cana por produto tradicionalmente produzido pelo estado, segue a análise do Shift-Share.

Os resultados do efeito substituição calculados a partir da Equação 4 podem ser visualizados na Tabela 4. É possível notar que entre 2002 a 2012, o maior efeito substituição é apresentado pelas parcerias de produção soja/milho (média de 740.040), acompanhado pela cana-de-açúcar (355.444). Em um primeiro momento, é admissível considerar que essas culturas são as principais substituintes das demais. Enquanto as culturas que exibem valores negativos possivelmente são aquelas que estão sendo substituídas, com grande destaque para a área de pastagem (-3.673.806).

Ainda, existem as variáveis Alim 1 e Alim 2, elas representam todas as culturas alimentares do estado de MS - sendo Alim 1 todas as culturas inclusive cana e Alim 2 todas as culturas exceto cana-de-açúcar, e ambos obtiveram os seguintes valores -1.836 .946 e -2.281.701. Devido às duas variáveis exibirem valores negativos é provável que as culturas milho, soja e cana-de-açúcar sejam as principais inibidoras do agregado das outras culturas alimentares e não apenas a cana-de-açúcar. Contudo, a variável Alim 2 possui menor média, evidenciando que a crescente presença da cana-de-açúcar esteja incitando disputas mais acirradas por área agricultável, mesmo quando ignorado o efeito substituidor da soja e milho.

Continuamente Martinelli et al. (2010) retratam que o avanço da produção agrária de uma região está atrelada ao aumento da produtividade ou à ocupação de áreas, os autores descrevem ainda que os dois processos descritos acima ocorrem de forma geral em todo o Brasil. Essa ocupação de área pode ser descrita como efeito cascata, em que uma agricultura em questão aumenta sua área sobre outras que, por sua vez, deslocam-se para outras regiões onde há espaço para ocupação.

Da mesma forma, as pesquisas de Oliveira (2003) e Spavorek (2007) concluíram que o fenômeno do avanço da produção entre culturas, já havia ocorrido no Mato Grosso do Sul. Essa primeira ocorrência deu-se da soja - desde a década de 1990 - sobre áreas onde já haviam lavouras tradicionalmente ocupadas com a produção de alimentos e com pastagens.

Entretanto, necessita-se de uma análise mais aprofundada a partir das informações obtidas pelo efeito substituição e da composição de área plantada agrícola do agregado histórico (Figuras 1). Assim para ilustrar esses cenários e indicar quais culturas afetam o espaço produtivo de outras, utilizou-se uma matriz de correlação com índices de correlação relativos a pares de culturas, que levam em consideração as mutações das áreas plantadas entre os períodos de 2000 a 2012. 
A Tabela 5 apresenta a matriz de coeficientes de Correlação de Spearman entre os efeitos substituição das principais culturas do estado.

Antes de tudo, é imprescindível destacar os períodos de safras análogas, ou seja, compreendem épocas semelhantes para plantio e colheita, desse modo, têm-se num sentido correspondente as lavouras do milho, o sorgo e o trigo. E de outro lado a soja, o arroz, o algodão, o feijão e a mandioca. A cana-de-açúcar é comparável com todas as culturas, inclusive com a pastagem, sem (necessariamente) rotação.

TABELA 4 - Efeito Substituição entre os tipos de culturas cultivados no estado de MS entre 2000 a 2012

\begin{tabular}{cccc}
\hline Variável & $\mathrm{n}^{\text {o }}$ municípios & Valor & Descrição da variável \\
\hline Espasto & 78 & -3.673 .806 & $\begin{array}{c}\text { efeito substituição da pastagem } \\
\text { Alim 2 }\end{array}$ \\
Alim 1 & 78 & -2.281 .701 & $\begin{array}{c}\text { efeito subs. Todas as culturas alimentares } \\
\text { efeito subs. Todas as culturas alimentares e cana }\end{array}$ \\
Arroz & 29 & -1.836 .946 & efeito substituição cultura arroz \\
Essorgo & 59 & -53.757 & efeito substituição cultura sorgo \\
Trigo & 27 & -48.495 & efeito substituição cultura trigo \\
Feijão & 53 & -8.336 & efeito substituição cultura feijão \\
out. perman. & 78 & -4.767 & efeito substituição das culturas permanentes \\
Mandioca & 77 & -2.740 & efeito substituição cultura mandioca \\
Demais temp. & 78 & -305 & efeito substituição demais temporárias \\
Algodão & 14 & 15.069 & efeito substituição cultura algodão \\
Escana & 65 & 15.358 & efeito substituição cultura cana-de-açúcar \\
Essoja & 73 & 444.755 & efeito substituição cultura soja \\
Esmilho & 78 & 729.702 & efeito substituição cultura milho
\end{tabular}

Fonte: Elaborado pelos autores

TABELA 5 - Correlação de Spearman entre o efeito substituição entre as culturas do MS entre 2000 a 2012

\begin{tabular}{|c|c|c|c|c|c|c|c|c|c|}
\hline & Cana & Milho & Soja & Sorgo & Arroz & Trigo & Algodão & Feijão & Mand. \\
\hline \multicolumn{10}{|l|}{ Cana } \\
\hline Milho & $0,9120 * *$ & & & & & & & & \\
\hline Soja & $0,4890 * *$ & 0,3461 & & & & & & & \\
\hline Sorgo & $-0,3131$ & $-0,1263$ & 0,0164 & & & & & & \\
\hline Arroz & $-0,9120 *$ & $-0,8516^{*}$ & $-0,1593$ & $0,4065^{* *}$ & & & & & \\
\hline Trigo & $-0,5549^{*}$ & $-0,6373 *$ & 0,2747 & 0,3461 & $0,6593 * *$ & & & & \\
\hline Algod. & 0,0000 & 0,0164 & 0,2747 & $-0,4230$ & 0,2142 & 0,0329 & & & \\
\hline Feijão & $-0,5879 *$ & $-0,6263^{*}$ & $-0,1263$ & 0,3461 & $0,5549 * *$ & $0,5934 * *$ & $-0,2472$ & & \\
\hline Mand. & $-0,4065$ & $-0,5164 *$ & $-0,1648$ & $-0,5329 *$ & 0,3956 & 0,0824 & 0,5384 & 0,0494 & \\
\hline Past. & $-0,7967^{*}$ & $-0,7637^{*}$ & $-0,4890^{*}$ & 0,1923 & $0,6758^{* *}$ & $0,5439 * *$ & $-0,0329$ & 0,4560 & 0,3021 \\
\hline
\end{tabular}

*Correlação negativa - quando existe substituição entre culturas

**Correlação positiva - quando as culturas tem aptidão para o mesmo sentido

Fonte: Elaborado pelos autores 
Sendo assim, o ano-safra pode ser composto por duas culturas, e naturalmente um dos cultivos tende a ocupar a área da cultura que encerrou seu período produtivo, podendo ser exemplificado pela ocorrência natural no estado de MS, a safra da soja ser complementada pela safra do milho (soja/milho).

De tal modo, a Tabela 5 mostra evidências de que a cultura de cana-de-açúcar concorre com culturas alimentares como o arroz, o feijão, o trigo e pastagem. Enquanto, se comparados com as lavouras soja/milho, culturas destaques no estado, e principal fonte para ração animal, seguem o mesmo sentido da cana-de-açúcar (aumento de área) sem evidências diretas de concorrência.

Outro fato importante é identificado pela dinâmica envolvendo principalmente a cultura pastagem, que sofre alteração em seu espaço rural por mais da metade das culturas, sendo marginalizada pela cana-de-açúcar, milho/ soja, arroz e trigo. Entre as próprias culturas alimentares existem poucas alternâncias, centradas apenas sobre o arroz, trigo e pastagem.

A ampliação das lavouras de cana-de-açúcar no MS transcorre pela década de 2005 incentivada pela tecnologia flex-fuel, presente no país desde 2000, combinado a fatores difundidos nas agendas de debates internacionais como as mudanças climáticas e nova elevação do preço do petróleo reaqueceu a produção do etanol como fonte de energia limpa (CORDEIRO, 2008).
Essas transformações na estrutura produtiva tendem a ocorrer na região por interesses políticos e de mercado, entretanto devem-se dimensionar inclusive os ganhos sociais uma vez que o meio produtivo no caso em questão está relacionado também à oferta de alimentos, e o mesmo pode ser percebido pela redução em suas áreas de cultivo.

Martinelli et al. (2010) e Souza et al. (2007) destacam que a industrialização e o destino final da produção, a principio, determinam a pauta produtiva, e nesse caso associam-se às chamadas culturas de exportação como soja/milho e cana, em virtude de políticas expansionistas do estado que favorecem a produção em larga escala.

Todavia, mesmo com a redução da área de produção de alguns alimentos, houve uma compensação pela produtividade adquirida em algumas situações como é demostrado na Tabela 6.

Logo a diminuição de área de alocação de algumas culturas alimentares é compensada pelo aumento de produtividade das mesmas. Gasques et al. $(2007,2011)$ apontam que o significativo aumento da produtividade é conexo aos fatores de produção e não apenas pela incorporação de novas áreas de cultivo.

Os fatores produtivos que contribuíram para o aumento da produtividade das agriculturas alimentares repousam sobre agricultores tecnificados, que utilizam tecnologias propícias para melhorar o sistema de produção,

TABELA 6 - Produtividade por hectare

\begin{tabular}{cccccc}
\hline & Arroz & Feijão & Sorgo & Trigo & Pastagem* \\
\hline 2000 & 3430 & 861 & 1330 & 993 & 742.028 \\
2001 & 4179 & 1271 & 2012 & 1732 & 840.976 \\
2002 & 4337 & 1010 & 2286 & 946 & 855.341 \\
2003 & 4836 & 1275 & 2411 & 1854 & 866.567 \\
2004 & 4477 & 1121 & 2418 & 1391 & 874.541 \\
2005 & 4362 & 1133 & 2588 & 1426 & 935.283 \\
2006 & 4453 & 1207 & 2120 & 1248 & 990.070 \\
2007 & 4956 & 1200 & 2594 & 1259 & 869.588 \\
2008 & 5319 & 1088 & 2608 & 1589 & 692.096 \\
2009 & 5315 & 932 & 2236 & 1713 & 725.087 \\
2010 & 5381 & 1373 & 2473 & 1875 & 722.566 \\
2011 & 5341 & 1270 & 2460 & 1393 & 702.075 \\
2012 & 6372 & 1643 & 3182 & 1619 & 747.912 \\
\hline
\end{tabular}

*Tonelada equivalente-carcaça

Fonte: Elaborado pelos autores

Organizações Rurais \& Agroindustriais, Lavras, v. 18, n. 3, p. 273-288, 2016 
como na adubação, tratamento de sementes, controle de pragas e utilização de variedades de sementes adequadas às condições climáticas de sua região.

No entanto, com o passar do tempo o aumento da produtividade de algumas lavouras pode ficar comprometido caso ocorra sucessivas vezes redução em sua área plantada. Assim adentra-se sobre uma abordagem concomitante a essa discussão, que remonta ainda reflexões sobre a estrutura fundiária, que por sua vez complementa o entendimento sobre a dinâmica dos usos e coberturas da terra.

Assim é pertinente ressaltar que a expansão da cana no estado de MS não se deu de forma uniforme em todos os municípios. A ampliação do cultivo da cana está associada a incentivos governamentais e estudos de solos propícios para seu cultivo e envolve também a questão de logística de transporte, pois existe a distância favorável entre a usina e as plantações (CENTENARO, 2012).

Os arranjos a seguir apontam em quais municípios as plantações de cana-de-açúcar foram alocadas, e o espaço ocupado em área, determinando a estrutura fundiária do estado. Em 2012, apenas 57 municípios de MS cultivavam a cana-de-açúcar, e desses, apenas 23 apresentaram Quociente Locacional para cana maior que 1 , indicando a concentração dessa cultura nessas regiões.
A Figura 2 expõe como estão distribuídos esses 23 municípios. Os valores de Quociente Locacional de 1,0 a 6,7 são aqueles em que a produção de cana-de-açúcar tem predominância em praticamente toda área agricultável em uso, a evidência maior desse cultivo está nas regiões que apresentam valor maior que 2,5.

Visualizam-se na Figura 2 os municípios que certamente deixam de produzir alimentos, principalmente os com QL acima de 2,5 totalizando 11 municípios, uma vez que da totalidade de suas áreas produtivas, a maior parte está disposta para o cultivo de cana-de-açúcar.

Adverte-se que esse índice não é fator decisivo para concluir a baixa produção de alimentos no estado de MS, mesmo porque o total de área colhida desses municípios é desprezível (municípios até 25.000 hectares), mas apenas existe a ascensão da cultura da cana sobre as demais lavouras temporárias.

E por esse motivo o Coeficiente de Especialização, Figura 3, traz os municípios com certa tendência para a especialização produtiva da cana, com destaque para o município de Aparecida do Taboado, que tem como área total colhida, em 2012, de 23.235 hectares, destes, 23.140 eram destinados apenas para a cana.

Além disso, no Coeficiente de Especialização nota-se certa semelhança com o Quociente Locacional, pois esses índices estão intimamente relacionados, porque

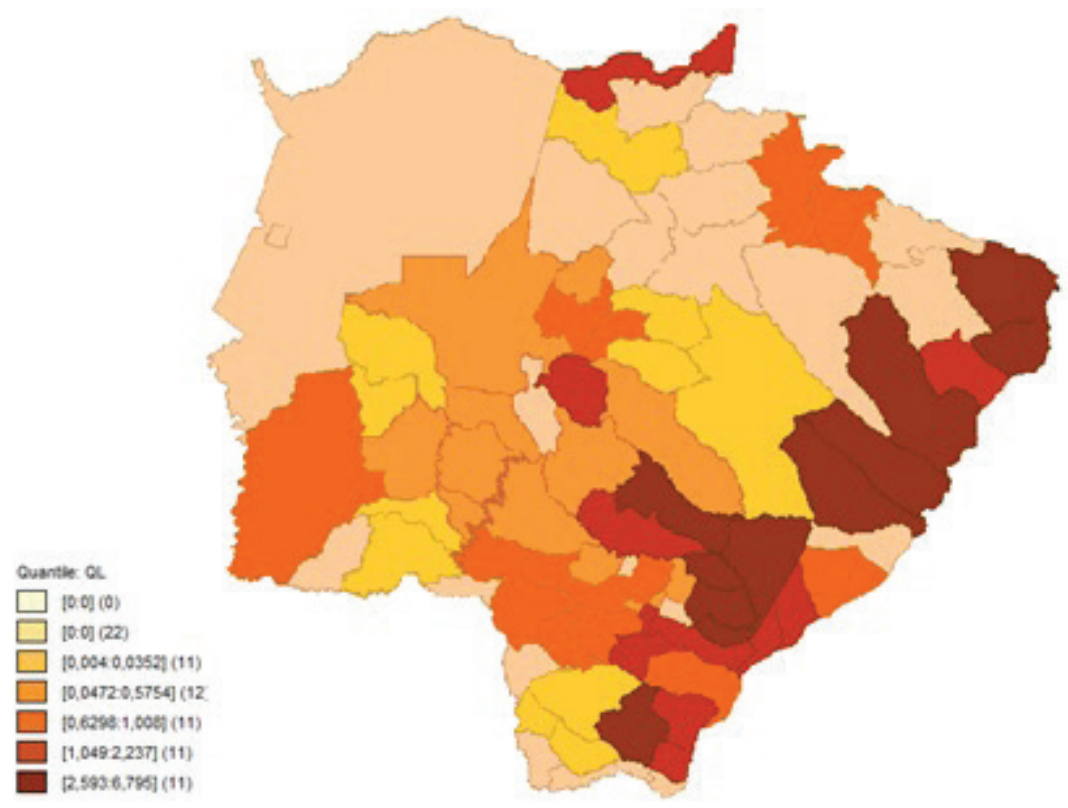

FIGURA 2 - Quociente Locacional da cana-de-açúcar em 2012 Fonte: IBGE. Elaborado pelos autores

Organizações Rurais \& Agroindustriais, Lavras, v. 18, n. 3, p. 273-288, 2016 
é muito provável que regiões que tenham QL alto para certa cultura também apresentem especialização para o cultivo das mesmas.

Entretanto esses municípios com elevados QL e CE para cana-de-açúcar sobre o total da produção agrícola no estado não são significativos. $\mathrm{O}$ destaque principal de especialização na maior parte do estado de MS é pelo cultivo da soja/milho.

Enquanto isso, juntamente ao valor do Índice de Theíl, na Figura 4, é possível constatar que quanto maior a diversificação da atividade agrícola do município, maior também é o nível de especialização para cada atividade. Os municípios que apresentam maior difusão da atividade agrícola possuem em sua composição o cultivo da cana-de-açúcar, mas isso não significa que há a predominância da cana-de-açúcar nessas regiões, mas sim há uma proporção maior para o cultivo da cultura.

A Figura 4 apresenta como está a distribuição dos municípios com relação aos índices relevantes para a produção de cana-de-açúcar no estado de MS, sendo que valores mais importantes estão acima de 0,1 . Neste caso não existe a predominância da cana, e são localidades com extensas áreas agricultáveis. No entanto, faz-se necessário uma reflexão sobre a quantidade de área colhida para o período de 2012, que até meados de 2000 era irrelevante, retomando a questão de substituição entre culturas para o cultivo da cana-de-açúcar.

Assim sendo, os municípios que aparecem com maior representatividade no Índice de Theíl constituem-se os mais importantes na produção de cana-de-açúcar para o estado de MS do que aqueles que detêm apenas maior Quociente Locacional e Coeficiente de Especialização.

É possível ainda identificar na Figura 5 o número e tamanho dos estabelecimentos agropecuários no estado de MS e respectivamente nos municípios onde a cana-de-açúcar expandiu-se, dividida de acordo com as categorias de propriedades - minifúndios, pequenas, médias ou grandes propriedades

Albuquerque (1987) define as categorias segundo a classificação a seguir: menores de 10 hectares, de 10 e menos de 100 hectares, de 100 a menos que 1.000 hectares e as mais de 1.000 hectares, essa classificação retrata a categoria do estabelecimento respectivamente em minifúndio, pequena, média e grande propriedade.

Há uma predominância de propriedades agropecuárias com grandes dimensões, que apesar do pouco número de imóveis rurais dessa categoria, estes ocupam praticamente $75 \%$ das áreas cultivadas em 2012. Entre os anos de 1995 a 2012, as áreas das grandes propriedades vieram diminuindo $2,7 \%$.

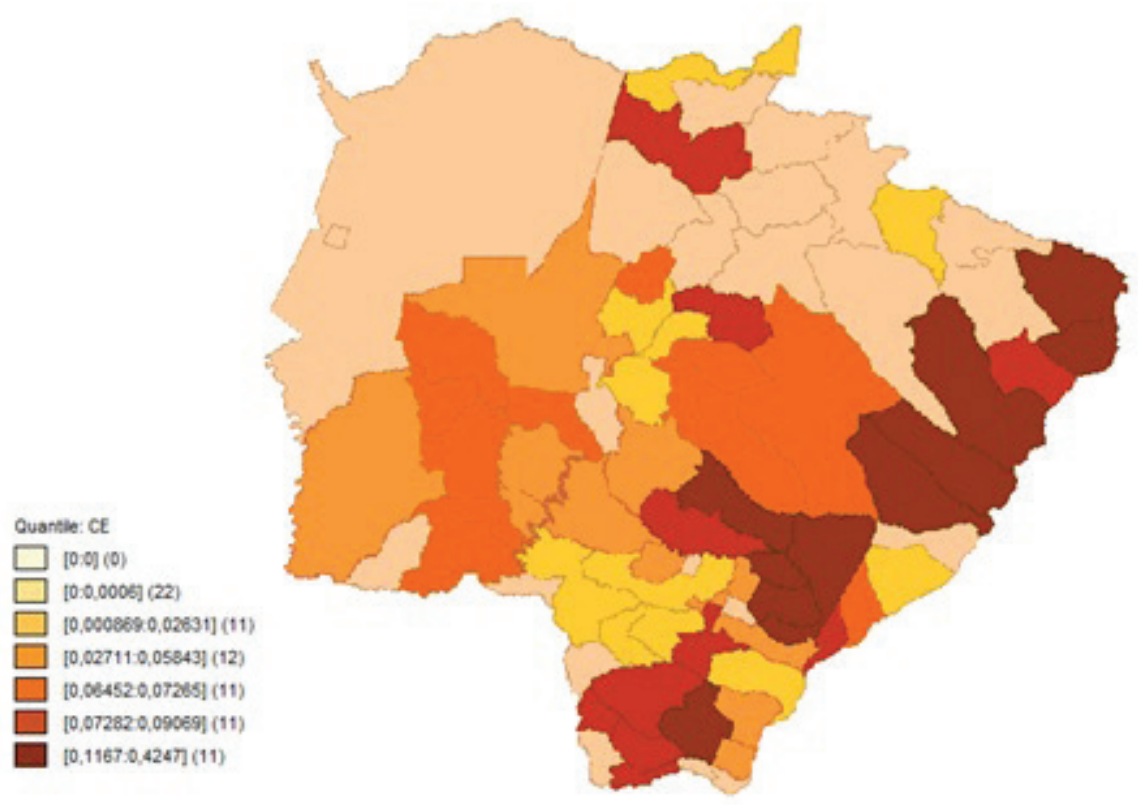

FIGURA 3 - Coeficiente de Especialização da cana-de-açúcar em 2012

Fonte: IBGE. Elaborado pelos autores

Organizações Rurais \& Agroindustriais, Lavras, v. 18, n. 3, p. 273-288, 2016 


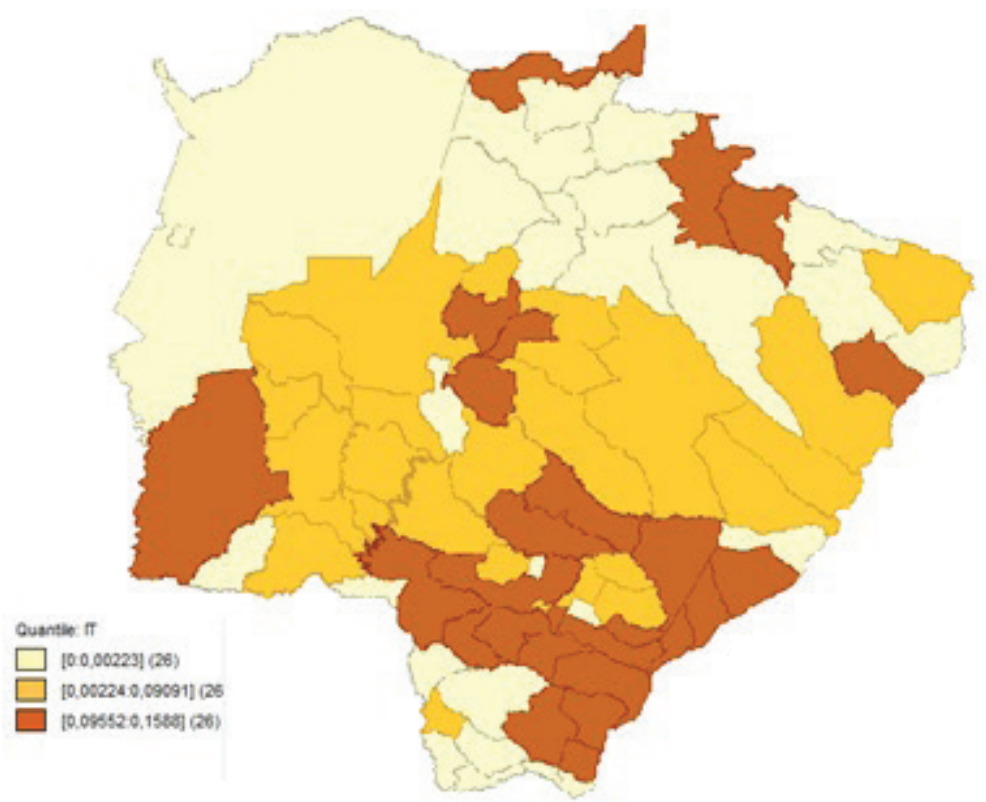

FIGURA 4 - Índice de Theíl da cana-de-açúcar em 2012

Fonte: IBGE. Elaborado pelos autores
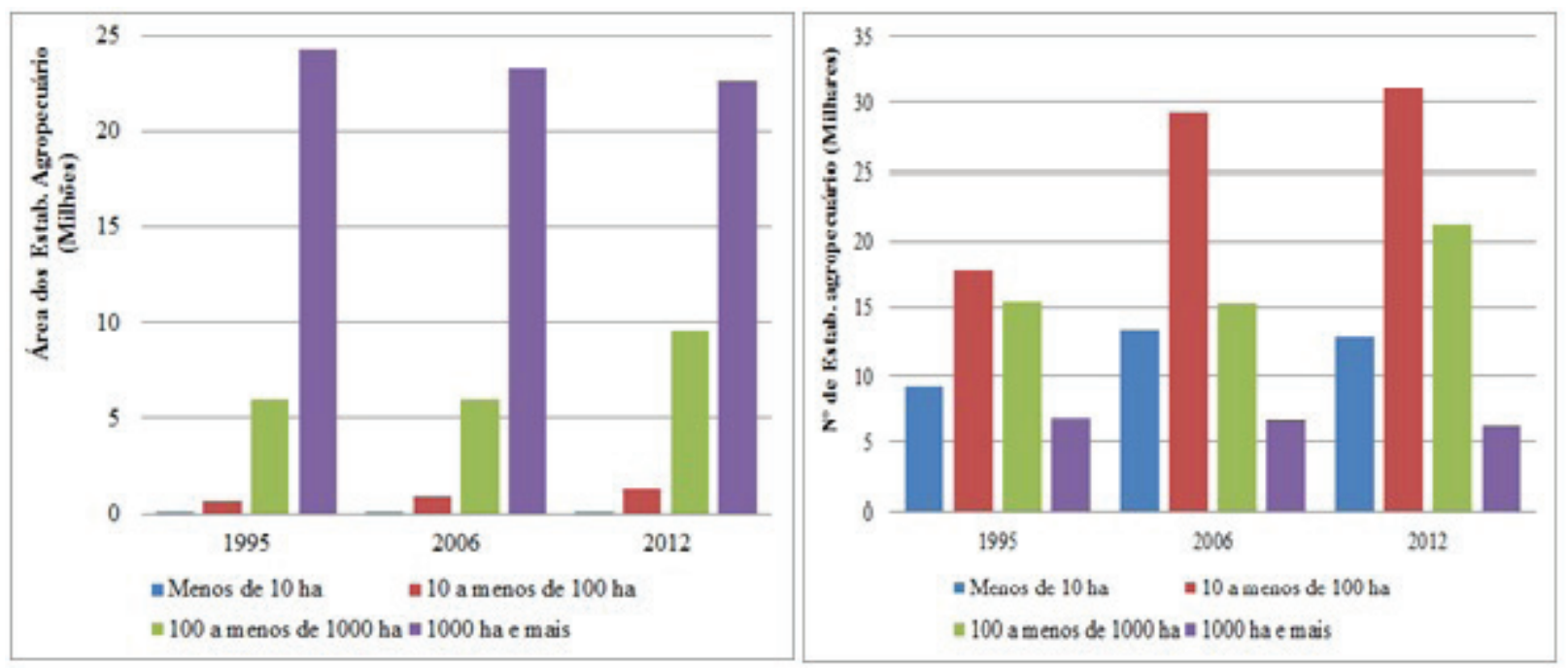

FIGURA 5 - Categorias de propriedades rurais no MS em 2012

Fonte: Elaborado com base nos dados do IBGE, Censo Agropecuário 1995/2006 e MDA/INCRA, 2012

As demais categorias fundiárias aumentaram suas áreas, notoriamente as médias propriedades foram as que mais expandiram, pouco mais de $59 \%$, passando de 5,99 milhões de hectares em 1995 para 9,53 milhões de hectares em 2012. Seguida pelas pequenas propriedades com aproximadamente $40 \%$ de expansão, mas até 2012 não chegavam a 1,0 milhão de hectare. Os minifúndios tiveram aumento, embora ainda a composição dessa categoria seja relativamente baixa com apenas 74.250 mil hectares.

A composição do número de estabelecimentos agropecuários acompanhou esse ajuste de áreas por 
categorias, e também tiveram maiores aumento as propriedades médias, seguidas pelos pequenos estabelecimentos.

As decomposições dos extratos por estabelecimentos mantêm a estrutura de concentração fundiária, organizado sob o domínio de poucos produtores/empresas com o propósito na produção de lavouras voltadas para o mercado exportador, pela influente consolidação do mercado agrícola (SOUZA et al., 2007, REYDON, 2007; D’ANTONA et al., 2011).

É notável que as estruturas do setor sucroenergético estejam alocadas em regiões com propriedades de médias a grandes extensões rurais, pois há a redução de área das grandes propriedades que são revertidas em maior parte para abertura de estabelecimentos medianos, e uma parcela menor revertido à abertura de novas pequenas propriedades, muito provável através de reforma agrária, destinadas a agricultura familiar.

E nesse sentido é relevante salientar que no estado de Mato Grosso do Sul a produção voltada ao mercado de exportação tem maior ênfase, em virtude do saldo positivo em sua balança comercial a partir da produção da cana, soja e milho, do que a produção voltada ao mercado interno, e principalmente aquela voltada à produção alimentar.

\section{CONSIDERAÇÕES FINAIS}

Num primeiro momento, é possível advertir que a produção de alimentos, teve perdas em suas áreas produtivas, essas áreas compreendem o início da expansão da cana-de-açúcar, com início no ano de 2000 e expansão em 2005. As lavouras mais prejudicadas são sorgo, arroz, trigo, feijão e as áreas de pastagem.

É importante lembrar também que as próprias culturas alimentares também substituíram outras produções alimentares, protagonizadas pela soja e milho, entretanto em menor magnitude quando comparada com o efeito da cana-de-açúcar sobre os demais alimentos, exemplos dessa situação foram identificados com o trigo e arroz.

Essa situação está ligada fortemente ao impulso na balança comercial, isto é, os produtos que melhor se comportam no mercado, em virtude de preços, são aqueles que recebem apoio governamental para que se expandam, nesse caso a cana-de-açúcar, a soja e o milho.

A participação da lavoura de cana-de-açúcar (na produção do biocombustível etanol) somente não excedeu o limite de ocupação de áreas devido a alguns fatos: a existência do zoneamento regulamentar, a necessidade de infraestrutura adequada para plantio e processamento, e ainda possuir alta produtividade e máximo reaproveitamento de seus dejetos.

Com relação à estrutura fundiária, pode-se inferir que a alocação das plantações de cana-de-açúcar nos municípios que representam o estado nessa lavoura, em nenhum deles há a predominância canavieira, existe apenas a diversificação de lavouras, apesar de estar altamente vinculada àquelas culturas de força de mercado e em grau baixíssimo para culturas alimentares.

Assim como permanece a produção em larga escala de culturas voltadas ao mercado externo, há um movimento contínuo de concentração fundiária, o que se torna preocupante, uma vez que isso acarreta a não propensão à produção de alimentos.

Dessa forma, avalia-se que a cultura da canade-açúcar tem relação com a substituição de culturas alimentares no estado de Mato Grosso do Sul, entretanto, não ameaça a segurança alimentar em um primeiro instante, devido ao aumento de produtividade das lavouras de alimentos. Mas é importante ressaltar a participação de políticas que incentivem a produção de alimentos assim como é estimulado a produção de produtos primordiais para a exportação.

\section{REFERÊNCIAS BIBLIOGRÁFICAS}

ABDALA, K; RIBEIRO, F. L. Análise dos impactos da competição pelo uso do solo no estado de Goiás durante o período 2000 a 2009 provenientes da expansão do complexo sucroalcooleiro. Revista Brasileira de Economia, v. 65, n. 4, p. 373-400, 2011.

AGRIANUAL. Anuário da Agricultura Brasileira. São Paulo: FNP Consultoria \& Comércio, 2007.

AGRIANUAL. Anuário da Agricultura Brasileira. São Paulo: FNP Consultoria \& Comércio, 2013.

ALBUQUERQUE, M. C. C. Estrutura fundiária e reforma agrária no Brasil. Revista de Economia Política, vol. 7, n. 3, jun/set. 1987.

ANUALPEC. Anuário estatístico da pecuária de corte. São Paulo: FNP Consultoria e Comércio Ltda., 2013.

BARBIER, E. B.; BURGESS, J.C.; GRAINGER, A. The forest transition: Toward a more comprehensive theoretical framework. Land Use Policy, Londres, v.27, n. 2, p.98 $-107,2010$. 
BARRETT, C. B. Measuring food insecurity. Science, v. 327, n. 5967, p. 825-828, 2010.

BIERHALS, J; FERRAZ, J. V. Há muita terra para produzir alimentos e energia. Agrianual, 2012.

BONELIL, R.; FLEURY, P. F; FRITSCH, W. Indicadores microeconômicos do desempenho competitivo. Revista de Administração da Universidade de São Paulo, v. 29, n. 2, 1994.

BRIASSOULIS, H. Analysis of land use change: theoretical and modeling approaches. In: Regional Research Institute of Wets Virginia University. The Web Book of Regional Science. Morgantown: Scott Loveridge, 2000. Disponível em < http:/www.rri.wvu. edu/WebBook/ Briassoulis/contents.htm $>$ Acesso em 01/03/2014.

BURITY, V.; FRANCESCHINI, T.; VALENTE, F.; RECINE, E.; LEÃO, M.; CARVALHO, M. F. Direito humano à alimentação adequada no contexto da segurança alimentar e nutricional. Brasília, DF: ABRANDH, 2010.

CENTENARO, M. Um estudo sobre investimentos direto externo no setor sucroenergético do estado de Mato Grosso do Sul. Tese (Doutorado em Administração) Universidade do Vale do Rio dos Sinos, UNISINOS, 2012.

CORDEIRO, Â. Etanol para alimentar carros ou comida para alimentar gente? In: Brasil. Impactos da indústria canavieira no Brasil. Plataforma BNDES: IBASE Instituto Brasileiro de Análises Sociais e Econômicas, 2008.

D’ANTONA, A; VANWEY, L; LUDEWIGS, T. Polarização da estrutura fundiária e mudanças no uso e na cobertura da terra na Amazônia. Acta Amazonica., Manaus, v. 41, n. 2, p. 223-232, 2011.

FAO, Food and Agriculture Organization. FAOSTAT. Disponível em: < http://faostat3.fao.org/download/Q/ QC/E > Acesso em: 23/08/2016.

FAO, Food and Agriculture Organization. FAO Statistical Yearbook 2013: World food and agriculture. Disponível em: < http://www.fao.org/docrep/018/i3107e/i3107e00. htm $>$ - Acesso em 10/03/2014.

FAO, Food and Agriculture Organization. The State of Food Insecurity in the World (SOFI) 2002.
Organização das Nações Unidas para a Agricultura e Alimentação: Roma, Itália. Disponível em: < http://www. fao.org/docrep/005/y7352e/y7352e 02.htm $>$. Acesso em 07/05/2014.

GARNETT, T; APPLEBY, M. C; BALMFORD, A; BATEMAN, I. J; BENTON, T. G; BLOOMER, P; BURLINGAME, B; DAWKINS, M; DOLAN, L; FRASER, D; HERRERO, M; HOFFMANN, I; SMITH, P; THORNTON, P. K; TOULMIN, C; VERMEULEN, S. J; GODFRAY, H. C. J. Sustainable Intensification In Agriculture: Premises And Policies. Science, vol. 341, n. 6141, p. 33-34, 2013.

GAsques, J. G; BASTOS, E. T; BACCHI, M. Produtividade e crescimento da agricultura brasileira. Brasília: MAPA, 2011. Nota técnica da Coordenação Geral de Planejamento Estratégico.

GASQuES, J. G; BASTOS, E. T; CONTINI, E; SAAB, A. A; SILVA, L. D. Projeções do agronegócio mundial e do Brasil. Ministério da Agricultura, Pecuária e Abastecimento (MAPA), Assessoria de Gestão Estratégica (AGE). 2007. Disponível em: < www.sober.org.br/palestra/6/1127.pdf $>$. Acesso em 18/02/2010.

IBGE, Instituto Brasileiro de Geografia e Estatística. 2014a. Estados. Disponível em < http://www.ibge.gov.br/ estadosat/perfil.php?sigla $=\mathrm{ms}>$. Acesso em 28/02/2014.

KOHLHEPP, G. Análise da situação da produção de etanol e biodiesel no Brasil. Estudos Avançados, v. 24, n. 68, p. 223-253, 2010.

LAMBIN, E. F.; GEIST, H. J.; LEPERS, E. Dynamics of land-use and land-cover change in tropical regions. Annual Review of Environment and Resources, Califórnia, v. 28, n. 1, p. 205-241, 2003.

LIMA, D. A. L. L.; LUNAS, A. L.; GARCIA, J. R.; GOMES, L. C.F.; GIONGO, P. R.; GONÇALES, C. Expansão do setor sucroenergético no sudoeste goiano: evolução e impactos sobre o uso do solo. Espacios. v. 35, n. 9, p. 152014.

MACEDO, D. C.; TEIXEIRA, E. M. B.; JERÔNIMO, M.; BARBOSA, O.A.; OLIVEIRA, M. R. M. de. A construção da política de segurança alimentar e nutricional no Brasil. Revista Simbio-logias, v. 2, n.1, 2009. 
MALUF, R.; MENEZES, F.; MARQUES, S. B. Caderno "Segurança Alimentar". Fórum Social Mundial. Paris: FHP, 2000.

MARTINELli, L. A.; JOLY, C. A.; NOBRE, C. A.; SPAROVEK, G. A falsa dicotomia entre a preservação da vegetação natural e a produção agropecuária. Biota Neotrop. v. 10, n. 4, p.323-330, 2010.

MELLO, E. S.; BRUM, A. L. O direito ao desenvolvimento e produção local: o plantio direto da soja como alternativa de desenvolvimento econômico. Revista Gedecon. v. 1, n. 1, p. 133-154, 2013.

OLIVEIRA, T. C. M. Agroindústria e reprodução do espaço. Campo Grande: Ed. UFMS, 2003.

PAULINO, R. T. Estrutura fundiária e dinâmica socioterritorial no campo brasileiro. Mercator, Fortaleza, v. 10, n. 23, p. 111-128, 2011.

REYDON, B. P. A regulação institucional da propriedade da terra no Brasil. In: RAMOS, P. et. al. Dimensões do agronegócio brasileiro: políticas, instituições perspectivas. Brasília: MDA, p.226-262, 2007.

RIBAS, P. M. Cultivo do sorgo. Embrapa, 2007. Disponível em < http://www.cnpms.embrapa.br/publicacoes/sorgo 3 ed/importancia.htm $>$ Acesso em 11/12/2014.
SCHLESINGER, S. O gado bovino no Brasil. 2010.

SOUZA, P. M; PONCIANO, N. J; MATA, H. T. C. Estrutura fundiária das regiões Norte e Noroeste do Estado do Rio de Janeiro: 1972 a 1998. Revista de Economia e Sociologia Rural, Rio de Janeiro, v. 45, n.1, p. 071-091, 2007.

SOUZA, P. M.; LIMA, J. E. Mudanças na Composição da Produção Agrícola no Brasil, 1975-95. Revista Econômica do Nordeste, Fortaleza, v.33, n.3, p. 632659, 2002.

SPAROVEK, G.; BERNDES, G.; EGESKOG, A.; FREITAS, F.L.M.; GUSTAFSSON, S.; HANSSON, J. Sugarcane ethanol production in Brazil: an expansion model sensitive to socioeconomic and environmental concerns. Biofuels, Bioproducts and Biorefining, v. 1, n. 4 , p. $270-282,2007$.

WATANABE, M. Uso da terra nos estado do Paraná, Brasil. Tese (Doutorado em Agronegócios) Universidade Federal do Rio Grande do Sul, UFRGS, 2009.

WISSMANN, M. A. et al. Evolução do cultivo da canade-açúcar na região Centro-Oeste do Brasil. Revista Brasileira de Desenvolvimento Regional, v. 2, n. 1, p. 095-117, 2014.

Organizações Rurais \& Agroindustriais, Lavras, v. 18, n. 3, p. 273-288, 2016 